\title{
Efeito do Programa Bolsa Família sobre a oferta de trabalho das mães ${ }^{1}$

\author{
Priscilla Albuquerque Tavares ${ }^{2}$
}

\section{Resumo}

Este artigo investiga a existência de um possível incentivo adverso à oferta de trabalho (participação no mercado e jornada) das mães beneficiadas pelo Programa Bolsa Família. Utiliza-se o procedimento de propensity score matching para encontrar mães não atendidas pelo programa comparáveis às mães atendidas, a partir de três grupos de controle. Os resultados apontam a existência de um efeito-renda associado ao valor do benefício, uma vez que quanto maior a transferência recebida, menor o engajamento da mãe no mercado de trabalho. Entretanto, o efeito líquido de ser beneficiário do programa é positivo, indicando a existência de um efeito-substituição, provavelmente decorrente da redução da oferta de trabalho dos filhos, da maior disponibilidade de tempo das mães para trabalhar ou mesmo do estigma em participar do programa.

Palavras-chave: Programa Bolsa Família; Oferta de trabalho feminina; Incentivos adversos; Pareamento; Procedimento de Heckman.

\section{Abstract \\ The impact of the Bolsa Familia Program on the labor supply of working mothers}

This paper investigates the existence of a possible adverse incentive on the labor supply and weekly working hours of beneficiary mothers of the Bolsa Família Program. Three control groups are analyzed using propensity-score matching to compare non-beneficiary mothers to beneficiary mothers. The results show that there is a wealth effect related to the value of the benefits, given that the larger the benefit, the less active beneficiary mothers are in the labor market. Nonetheless, the net effect is positive, showing that there is a substitution effect due to a reduction in the children's labor supply, a rise in the mother's available time, as well as decreasing the stigma.

Key words: Bolsa Família Program; Female labor supply; Adverse incentives; Matching; Heckman's procedure.

JEL J18, J22.

\section{Introdução}

Os programas de transferência de renda com condicionalidades têm sido adotados por muitos países em desenvolvimento como estratégias para a redução da pobreza e da desigualdade social. O Programa Bolsa Família (PBF) constitui-se na maior política de assistência social brasileira. O PBF foi criado em 2004, com a finalidade de unificar a gestão e a execução das ações de transferência de renda de outros programas preexistentes: Bolsa Escola, Bolsa Alimentação, Auxílio-Gás e

(1) Trabalho recebido em maio de 2007 e aprovado em agosto de 2009.

(2) Professora da Universidade Presbiteriana Mackenzie e Assessora Técnica em Pesquisas Educacionais na Secretaria da Educação do Estado de São Paulo, São Paulo, SP, Brasil. E-mail: pri_fea@yahoo.com.br. 
Fome Zero. ${ }^{3}$ Atualmente, o PBF destina cerca de R\$ 12 bilhões $^{4}$ ao atendimento de mais de 11 milhões de famílias.

O governo federal visa assistir famílias em situação de pobreza e extrema pobreza, compostas por crianças com idade entre zero e quinze anos e/ou gestantes. Considera-se pobre ou extremamente pobre a unidade familiar cuja renda per capita mensal seja igual ou inferior a $\mathrm{R} \$ 120,00$ e $\mathrm{R} \$ 60,00$, respectivamente..$^{5} \mathrm{O}$ benefício varia de acordo com a renda e a composição familiar. Famílias extremamente pobres recebem um valor fixo de $\mathrm{R} \$ 58,00$ mensais. Além disso, é concedido a todas as famílias beneficiárias um aditamento variável de $\mathrm{R} \$ 18,00$ por criança inscrita no programa, para no máximo três crianças por família. ${ }^{6}$

Mais do que uma política de assistência social, o PBF vincula a garantia de uma renda mínima ao cumprimento de condicionalidades. A preocupação do programa é garantir a segurança alimentar e boas condições de saúde e promover o acesso e a manutenção das crianças na escola. Assim, exige-se a realização de exames pré-natal para as gestantes; acompanhamento médico, atualização de vacinas e manutenção de peso e altura adequados das crianças de zero a seis anos; a matrícula regular e frequência de no mínimo $85 \%$ das aulas para as crianças de 7 a 15 anos. $^{7}$

Dessa forma, além de buscar aliviar a pobreza no curto prazo por meio da transferência direta de renda, o programa caracteriza-se como uma política de longo prazo na medida em que procura criar condições para a geração autônoma de renda no futuro por meio do investimento em capital humano e da interrupção do ciclo de perpetuação da pobreza.

\section{Revisão da literatura acerca das avaliações do Bolsa Família}

$\mathrm{O}$ PBF tem sido objeto de diversas avaliações recentes. Um consenso na literatura é a de que o programa é bem focalizado. Tavares et al. (2008) mostram

(3) Os programas Bolsa Escola, Bolsa Alimentação e Fome Zero também eram chamados de Programa Nacional de Renda Mínima vinculado à Educação, Programa Nacional de Renda Mínima vinculado à Saúde e Programa Nacional de Acesso à Alimentação.

(4) Orçamento Geral da União de dezembro de 2008.

(5) Em 2004, quando o programa foi implantado, os valores de corte eram de $\mathrm{R} \$ 100,00$ e $\mathrm{R} \$ 50,00$.

(6) O recebimento do benefício fixo independe da existência de crianças em idade de 0 a 15 anos ou de gestantes na família. Quando o programa foi implantado, os benefícios eram de R \$ 50,00 (fixo) e R \$ 15,00 (variável). Em 2008, o programa também passou a atender os jovens de 16 e 17 anos, residentes em famílias já beneficiárias, com uma transferência de $\mathrm{R} \$ 30,00$ por jovem.

(7) Estas condicionalidades já eram impostas pelos programas Bolsa Escola e Bolsa Alimentação. No entanto, como mostram Marques et al. (2009), o Bolsa Família tornou-se um programa mais amplo do que aqueles que o originaram, tanto por sua maior cobertura quanto pelo fato de conceder um benefício fixo para famílias extremamente pobres. 
que o PBF inclui 50\% das famílias elegíveis em nível nacional, chegando a atender $70 \%$ do público-alvo em estados pobres como o Maranhão, Piauí, Ceará e Rio Grande do Norte. Marques (2005) ressalta que o programa chega a atender $45 \%$ da população de diversos municípios nordestinos, região com maior concentração de beneficiários $(69,1 \%)$. Soares et al. (2006) indicam que $80 \%$ dos recursos do PBF são destinados a famílias pobres.

O impacto do PBF sobre a melhoria dos indicadores de vulnerabilidade social no período recente também é expressivo. Ipea (2007) e Soares et al. (2006) consideram que cerca de $10 \%$ a $20 \%$ da queda do Índice de Gini deve-se ao programa. Tavares et al. (2008) estimam que o benefício do programa responda por uma redução de 0,9 p.p. e de 1,1 p.p. na incidência de pobreza e extrema pobreza. Marques (2005) ressalta a importância do Bolsa Família para as atividades econômicas de municípios menos desenvolvidos.

Resende (2006) revela o aumento de bem-estar dos beneficiários, principalmente por conta do aumento do gasto com alimentos, vestuário, educação e artigos de higiene. O relatório do MDS (2007) ressalta ainda a importância do recebimento do benefício para o aumento no consumo de alimentos das famílias extremamente pobres (de cerca de $\mathrm{R} \$ 388$ por ano).

Diversos trabalhos abordam também a efetividade das condicionalidades impostas pelo PBF. Bourguignon et al. (2002) e Cardoso e Souza (2004) concluem que o programa é eficaz em elevar a frequência escolar das crianças beneficiárias. ${ }^{8}$ Pedrozo (2007) mostra que $91,2 \%$ das crianças beneficiárias que não frequentavam a escola passaram a estudar, sendo que $64,4 \%$ delas optariam por não trabalhar para se dedicar exclusivamente aos estudos. ${ }^{9}$ Ferro e Kassouf (2005), ${ }^{10}$ por sua vez, mostram que a jornada de trabalho das crianças atendidas pelo programa diminui em cerca de 3,0 horas semanais, o que possibilita maior dedicação à escola.

Os resultados para o Brasil não apontam para melhoras no status nutricional das crianças de seis a 60 meses incluídas no PBF (Cedeplar, 2006; Chein et al.; 2006). ${ }^{11}$ No entanto, na análise regional, o recebimento do benefício do programa parece estar associado a uma redução da desnutrição extrema nas regiões Norte e Centro-Oeste. ${ }^{12}$ Finalmente, também não se observa impacto

(8) Estes trabalhos de referem à avaliação do Programa Bolsa Escola e utilizam os dados da PNAD de 1999 e do Censo de 2000, respectivamente.

(9) O autor utiliza os dados da PNAD de 2004.

(10) Esta avaliação também se refere ao Programa Bolsa Escola.

(11) Os autores utilizam os dados da Pesquisa de Avaliação de Impacto do Programa Bolsa Família.

(12) Os resultados sobre as condições de saúde não são muito conclusivos, uma vez que são muito sensíveis à medida de desnutrição utilizada. 
significativo sobre a vacinação e a realização de exames de pré-natal entre os beneficiários do programa (MDS, 2007).

\section{Contribuição para a avaliação do Bolsa Família}

A implantação de políticas sociais pode incentivar mudanças de comportamento não desejáveis por parte dos beneficiários dos programas ${ }^{13}$ (Anuatti et al., 2001). Assim, a questão dos incentivos adversos é considerada um dos critérios de avaliação de políticas sociais e, na literatura de avaliação do Bolsa Família, ainda representa uma lacuna.

Quando se trata de programas de transferência de renda, o primeiro incentivo adverso que se suporia existir é o da redução da oferta de trabalho dos beneficiários, aumentando seu grau de dependência em relação ao programa, dada a redução da renda proveniente do trabalho. Este comportamento representaria o efeito-renda da transferência: diante do aumento da parcela da renda do domicílio, algum membro da família reduz sua oferta de trabalho sem comprometer o orçamento familiar. Também conhecido como 'efeito-preguiça', esta tem sido a principal crítica em relação ao PBF.

Em programas como o PBF, também se pode supor a existência de um efeito-substituição da transferência, decorrente da imposição de condicionalidades. Isso porque, como o programa atrela o recebimento do benefício à frequência das crianças às aulas, deve haver uma redução do trabalho infantil ofertado e, portanto, da renda do trabalho no domicílio, que poderia ser compensada pelo aumento do trabalho ofertado por outro membro da família. Assim, o impacto do programa sobre a oferta de trabalho dos beneficiários não é conclusivo, uma vez que depende de dois efeitos (renda e substituição), que atuam em sentidos opostos.

O objetivo deste artigo é contribuir para a avaliação do Bolsa Família, investigando a existência de possíveis incentivos adversos do programa com relação às decisões relacionadas à oferta de trabalho. ${ }^{14}$ Especificamente, procurase avaliar o impacto do programa sobre as decisões das mães residentes em famílias beneficiárias com relação à sua participação no mercado e à jornada de trabalho.

A opção de estudar o efeito do programa sobre as decisões de trabalho das mães (e não de outros membros da família) baliza-se nos seguintes fatos: a) a oferta de trabalho feminina é mais elástica. Isso porque seu salário de reserva é

(13) O caso mais conhecido da literatura refere-se à redução do esforço da busca por um novo emprego quando o indivíduo está protegido por uma política de seguro-desemprego.

(14) Medeiros et al. (2007) observam que a taxa de participação no mercado de trabalho é maior entre os beneficiários do PBF $(74,5 \%)$ do que entre os não beneficiários $(68,3 \%)$ e afirmam que ainda não existem resultados robustos acerca do impacto do programa sobre a oferta de trabalho. 
mais elevado, uma vez que precisa compensar o menor tempo dedicado aos filhos e aos cuidados domésticos; b) as mulheres têm maiores possibilidades de substituir um emprego no mercado de trabalho por atividades remuneradas executadas em casa ${ }^{15}$ c) o benefício do programa é recebido pelas mães, que têm a decisão de como alocar esse recurso nos gastos da família. Assim, é razoável supor que se a participação no programa for suficiente para desincentivar o trabalho, este efeito deve ser mais forte sobre as decisões de trabalho das mulheres.

O texto está organizado em outras cinco seções. Nas seções 3 a 5, apresentam-se a metodologia, os dados utilizados e os procedimentos econométricos empregados na análise. Nas seções 6 e 7, discutem-se os resultados encontrados e as principais conclusões.

\section{Metodologia}

A mensuração dos efeitos da participação em um programa social sobre uma variável de interesse (oferta e jornada de trabalho, por exemplo) refere-se à mudança dessa variável determinada pelo recebimento do benefício. A questão central em avaliações desse tipo é o estabelecimento de uma relação causal entre a participação no programa e as mudanças na variável de interesse.

O problema é que não é correto simplesmente comparar os indivíduos que recebem o benefício do programa com aqueles que não recebem. No caso deste artigo, não se poderia afirmar que o engajamento no mercado de trabalho das mães beneficiárias, caso elas não recebessem o benefício, poderia ser representado pelo engajamento no mercado de trabalho das mães não beneficiárias. Isso porque pode haver características que determinem a participação no programa e que também expliquem as decisões de oferta de trabalho.

Para medir o impacto da participação no PBF sobre a oferta de trabalho, o ideal seria comparar a participação e a jornada de trabalho de uma mesma mulher na situação de receber ou não o benefício. Entretanto, num dado momento do tempo, uma mulher apresenta apenas um status - a de ser ou não beneficiária do programa - de forma que não é possível observar suas decisões de engajamento nas duas situações.

Quando a seleção para um programa é aleatória, seu impacto é independente do fato de o indivíduo ser ou não beneficiário. Assim, caso a seleção para participação no PBF fosse aleatória, o impacto da participação no programa sobre as decisões de engajamento no mercado seria dado simplesmente pela diferença entre a participação no mercado de trabalho (ou a jornada) observada entre as mães que recebem e as que não recebem o benefício.

(15) Sobre questões acerca da oferta de trabalho feminina, ver Scorzafave e Menezes-Filho (2001); Soares e Izaki (2002).

Economia e Sociedade, Campinas, v. 19, n. 3 (40), p. 613-635, dez. 2010. 
Priscilla Albuquerque Tavares

Entretanto, a seleção para a participação do PFB não é aleatória. Ao contrário, ela depende: a) da autosseleção à participação, uma vez que o programa seleciona as famílias inscritas no Cadastro Único; e b) dos critérios de renda e composição da família. Desde que a família atenda aos requisitos de elegibilidade, a inclusão no programa segue a ordem de cadastramento.

Desse modo, as características da família (observáveis ou não) que determinam a participação no programa também podem estar associadas a decisões de engajamento no mercado de trabalho. Por exemplo, o local de residência e o grau de informação e entendimento das famílias com relação ao direito de receber o benefício poderiam se relacionar tanto à seleção ao programa como à oferta de trabalho: em regiões rurais, em que o cadastramento das famílias é mais difícil, também pode ser mais difícil encontrar um trabalho; além disso, pode-se supor que mães mais bem-informadas a respeito do programa também podem ser mais bem-informadas a respeito de vagas de emprego.

Assim, a estimação do impacto do PBF sobre as decisões de oferta de trabalho exige que se comparem mães 'comparáveis', ou seja, cujas características que determinam a participação no programa sejam semelhantes, o que seria equivalente a simular uma seleção aleatória. Por isso, escolheu-se como estratégia metodológica o método de propensity score matching. Basicamente, essa metodologia permite encontrar mães não beneficiárias que sejam semelhantes quanto às características observáveis às mães beneficiárias, a partir de grupos de controle selecionados.

Nesse procedimento, considera-se que a seleção ao programa é determinada por um conjunto de variáveis observáveis, de modo que, ao se comparar o grupo avaliado com um grupo de controle bastante semelhante quanto às variáveis observáveis, a única diferença potencial entre eles é a participação no PBF.

Um bom grupo de comparação deve servir como um contrafactual, ou seja, deve representar as mães beneficiárias na situação de não beneficiárias. Assim, os grupos de controle devem ser constituídos por mães que não sejam atendidas pela política, mas que sejam bastante semelhantes às mães atendidas quanto às características observáveis.

Nas duas próximas seções, apresentam-se os procedimentos adotados para levar a cabo essa metodologia.

\section{Dados e estratégias de identificação dos grupos}

O suplemento da PNAD de 2004 investiga questões sobre os programas de transferências do governo. No questionário de domicílios existem perguntas acerca 
do recebimento de cada programa social. ${ }^{16}$ Neste trabalho, são consideradas beneficiárias do PBF as famílias que declaram participar dos programas AuxílioGás, Bolsa Escola, Bolsa Alimentação e Fome Zero (Cartão Alimentação), ${ }^{17}$ além daquelas que de fato se declaram beneficiárias do próprio PBF.

Como a unificação dessas políticas ocorreu em 2004, supõe-se que ao declarar as informações ao recenseador da PNAD, alguns beneficiários não soubessem distinguir com clareza os diferentes programas, como ressaltam Soares et al. (2008). Desse modo, algumas pessoas ainda se consideravam beneficiárias dos programas originais, enquanto outras já se identificavam como beneficiárias do PBF. No entanto, em setembro de 2004, quando a pesquisa da PNAD é realizada, o Ministério de Desenvolvimento Social já havia incluído no Bolsa Família todos os beneficiários dos programas Auxílio-Gás, Bolsa Escola, Bolsa Alimentação e Fome Zero ou Cartão Alimentação, desde que estes cumprissem as exigências de inclusão no programa. Assim, a opção de considerar como beneficiários do PBF todos os incluídos nos programas que o constituem se faz necessária para que o número de famílias beneficiadas pelo programa não seja subestimado. $^{18}$

Na PNAD de 2004, o valor do benefício recebido por programas de transferência de renda está declarado na variável de 'outros rendimentos', ${ }^{19}$ que inclui juros de caderneta de poupança e de outras aplicações, dividendos e outros rendimentos. Para $31 \%$ das famílias incluídas no $\mathrm{PBF}$ não há qualquer valor declarado em 'outros rendimentos'; para outros 58\%, as quantias declaradas correspondem aos valores transferidos pelo $\mathrm{PBF} ;{ }^{20,}{ }^{21}$ para os $11 \%$ restantes, a quantia declarada é positiva, mas não corresponde exatamente aos valores típicos transferidos pelo programa.

Para os casos em que a quantia declarada difere dos valores transferidos pelo PBF, existem três explicações: a) a família declarou erroneamente o valor do

(16) As variáveis v2003 a v1600 referem-se aos programas Auxílio-Gás, Bolsa Família, Cartão Alimentação ou Fome Zero, Bolsa Alimentação, Benefício de Prestação Continuada - BPC/LOAS, Bolsa Escola e Programa de Erradicação do Trabalho Infantil - PETI.

(17) O PETI só foi incorporado ao PBF em 2006 e, portanto, beneficiários do PETI não serão incluídos na definição de beneficiários do PBF adotada aqui.

(18) Como mostram Soares et al. (2008), em 2004 o número de famílias inscritas no Cadastro Único para recebimento do Bolsa Família era de cerca de 9 milhões. Segundo os dados da PNAD de 2004, o número de famílias que se declaravam beneficiárias do PBF é de quase de 2,1 milhões. Já o número de famílias que se declaravam beneficiárias dos programas que passaram a compor o PBF é de 8,4 milhões. Isso mostra a importância da opção metodológica adotada neste artigo.

(19) Variável v1273 do questionário de pessoas.

(20) Estas porcentagens referem-se às famílias que têm mães presentes.

(21) Valores correspondentes ao recebimento do benefício referem-se a combinações dos valores de $\mathrm{R} \$ 50,00$ e múltiplos de $\mathrm{R} \$ 15,00$ (valores fixo e variável do PBF em 2004) e de $\mathrm{R} \$ 7,00$ e $\mathrm{R} \$ 8,00$ (correspondentes ao Auxílio-Gás, de $\mathrm{R} \$ 15,00$ bimestrais): $\mathrm{R} \$ 7, \mathrm{R} \$ 8, \mathrm{R} \$ 15, \mathrm{R} \$ 30, \mathrm{R} \$ 45, \mathrm{R} \$ 50, \mathrm{R} \$ 65$, $\mathrm{R} \$ 80, \mathrm{R} \$ 95, \mathrm{R} \$ 22, \mathrm{R} \$ 23, \mathrm{R} \$ 37, \mathrm{R} \$ 38, \mathrm{R} \$ 52, \mathrm{R} \$ 53, \mathrm{R} \$ 57$ e $\mathrm{R} \$ 58$.

Economia e Sociedade, Campinas, v. 19, n. 3 (40), p. 613-635, dez. 2010. 
benefício recebido; b) a família declarou corretamente o valor do benefício recebido, mas esse valor encontra-se somado a outros tipos de rendimentos declarados na mesma variável; c) o valor declarado refere-se exclusivamente a outros rendimentos, que não a transferência do benefício. Para os casos em que não há declaração, existem duas explicações: a) a família, erroneamente, não declarou o valor recebido; b) a família estava inscrita e aprovada para participar do programa, mas ainda não estava recebendo a transferência do benefício.

Dada a dificuldade de identificar exatamente o valor transferido às famílias, os trabalhos que analisam o Bolsa Família a partir dos dados da PNAD de 2004 procuram desagregar a variável 'outros rendimentos' em valores que se referem à transferência e em valores que se referem a outros rendimentos (juros e dividendos), partindo de algumas hipóteses que, obviamente, não solucionam o problema, mas procuram minimizá-lo. ${ }^{22}$

Neste trabalho, procedeu-se de forma semelhante a Soares et al. (2008): do valor total declarado, os valores típicos transferidos pelo PBF são considerados declarações do benefício do PBF (e contabilizados em 'valor do BF'); os valores excedentes são considerados declarações de juros e dividendos (e contabilizados em 'outras rendas'). ${ }^{23}$

Assim, as mães que declaram estar inscritas no programa e para as quais o 'valor do BF' é positivo constituem o 'grupo avaliado'. Já as mães que declaram estar inscritas no programa e para as quais o 'valor do BF' é zero constituem o 'grupo de controle 1'. Nesses dois grupos, incluem-se mães que se inscreveram no Cadastro Único (selecionaram-se a participar do programa) e foram aprovadas para receber o benefício. Ou seja, as mulheres que compõem esses dois grupos são, por hipótese, semelhantes quanto às características observáveis e não observáveis, tendo como única diferença o recebimento do benefício do Bolsa Família.

As mães do grupo avaliado também foram comparadas com outros dois grupos de mulheres que devem ser, por hipótese, semelhantes a elas quanto às características observáveis. O 'grupo de controle 2' é constituído por mães não beneficiárias que pertencem ao público-alvo do PBF (são pobres ou extremamente pobres), ou seja, inclui mulheres que, embora não sejam beneficiárias do programa, apresentam os requisitos necessários para a participação.

(22) Ver Soares et al. (2006); Soares et al. (2008); Medeiros et al. (2007); Foguel e Barros (2008).

(23) Por exemplo, se a declaração da família em 'outros rendimentos' é igual a $\mathrm{R} \$ 46,00$, consideram-se que $\mathrm{R} \$ 45,00$ devem-se ao benefício do programa e $\mathrm{R} \$ 1,00$ deve-se a juros e dividendos. As declarações de valores inferiores a $\mathrm{R} \$ 7,00$ (menor 'valor típico' observado) são inteiramente contabilizadas como 'outras rendas'. Tal procedimento procura separar as transferências e rendas de outra natureza, que são declaradas na mesma variável. No entanto, ele não resolve problemas de erros nas declarações. 
O 'grupo de controle 3' é constituído por mães não beneficiárias cuja renda familiar per capita é menor ou igual a $\mathrm{R} \$ 260,00$. A comparação com este grupo se justifica pelo fato de que, embora nem todas as famílias beneficiárias do PBF atendam rigorosamente aos critérios de elegibilidade, para a maior parte delas a renda ainda é baixa (em 95\% delas, a renda per capita não ultrapassa os $\mathrm{R} \$ 260,00$ mensais).

Foram consideradas mães as mulheres chefes ou cônjuges de famílias cuja diferença de idade com relação aos filhos estivesse entre 12 e 50 anos. A Tabela 1 a seguir apresenta as estatísticas descritivas acerca das características pessoais, de maternidade e de trabalho das mães do grupo avaliado e dos grupos de controle.

As mães beneficiárias e não beneficiárias assemelham-se bastante quanto às características pessoais: entre $34 \%$ e $45 \%$ delas são de cor branca; pouco mais de $70 \%$ têm cônjuge e pouco mais de $20 \%$ delas são chefes da família. As mães do grupo de controle 2 são mais novas (32 anos) do que as mães do grupo avaliado e dos grupos de controle 1 e 3 ( 37 ou 38 anos). As mães não beneficiárias são mais escolarizadas (entre 5 e 6 anos de estudos) do que as mães beneficiárias (4 anos de estudo).

As mães beneficiárias têm, em média, mais filhos (3) do que as mães dos grupos de controle (2). Os filhos das mulheres que compõem o grupo de controle 2 são mais novos dos que os filhos das mulheres do grupo avaliado e dos grupos de controle 1 e 3 . Isso pode ser visto tanto pela média de idade dos filhos mais novo e mais velho quanto pela porcentagem de mulheres com filhos em cada faixa etária.

Com relação às variáveis relacionadas ao mercado de trabalho, nota-se que a taxa de ocupação das mães do grupo avaliado (50\%) e dos grupos de controle $1 \mathrm{e}$ $3(48 \%$ e $42 \%)$ são semelhantes. Entretanto, uma porcentagem bem menor de mães do grupo de controle 2 exerce trabalho remunerado (32\%). Isso deve ser explicado pelo fato de que uma porcentagem maior das mães do grupo de controle 2 tem filhos pequenos (entre 0 e 5 anos). A jornada de trabalho semanal média para as mulheres que trabalham é muito semelhante entre as mães beneficiárias e não beneficiárias (entre 33 e 37 horas).

Os salários das mães dos grupos de controle 1 e 3 ( $\mathrm{R} \$ 228,6$ e $\mathrm{R} \$ 235,6$ ) são em média maiores do que os salários das mães do grupo avaliado ( $\mathrm{R} \$ 150,6)$, dada a maior escolaridade das primeiras. Apesar de as mães do grupo de controle 2 serem mais escolarizadas do que as mães do grupo avaliado, elas auferem salários menores $(\mathrm{R} \$ 123,7)$ e isso pode se dever ao fato de serem mais jovens (e, portanto, menos experientes no mercado de trabalho) e, novamente, ao fato de terem filhos mais novos. ${ }^{24}$

(24) Pazello e Fernandes (2004) mostram a existência de um efeito negativo da maternidade sobre o engajamento da mulher no mercado de trabalho e sobre os salários no curto prazo, ou seja, mulheres com filhos pequenos recebem salários menores do que mulheres sem filhos.

Economia e Sociedade, Campinas, v. 19, n. 3 (40), p. 613-635, dez. 2010. 
Tabela 1

Estatísticas descritivas

\begin{tabular}{|c|c|c|c|c|}
\hline Variáveis & $\begin{array}{l}\text { Grupo } \\
\text { avaliado }\end{array}$ & $\begin{array}{l}\text { Grupo de } \\
\text { controle } 1\end{array}$ & $\begin{array}{l}\text { Grupo de } \\
\text { controle } 2\end{array}$ & $\begin{array}{l}\text { Grupo de } \\
\text { controle } 3\end{array}$ \\
\hline \multirow{2}{*}{ Idade } & 37 & 37 & 32 & 38 \\
\hline & (11) & (13) & (10) & (14) \\
\hline \multirow{2}{*}{ Escolaridade } & 4 & 5 & 5 & 6 \\
\hline & (3) & (4) & (3) & (4) \\
\hline \multirow{2}{*}{$\%$ Mulheres brancas } & 0,34 & 0,42 & 0,35 & 0,45 \\
\hline & $(0,47)$ & $(0,49)$ & $(0,48)$ & $(0,50)$ \\
\hline \multirow{2}{*}{ \% Mulheres com cônjuge } & 0,74 & 0,72 & 0,74 & 0,71 \\
\hline & $(0,44)$ & $(0,45)$ & $(0,44)$ & $(0,45)$ \\
\hline \multirow{2}{*}{$\%$ Mulheres chefes } & 0,21 & 0,24 & 0,21 & 0,24 \\
\hline & $(0,40)$ & $(0,43)$ & $(0,41)$ & $(0,43)$ \\
\hline \multirow{2}{*}{ Número de filhos } & 3 & 2 & 2 & 2 \\
\hline & (1) & (1) & (1) & (1) \\
\hline \multirow{2}{*}{ Idade do filho mais novo } & 9 & 9 & 5 & 10 \\
\hline & (8) & (9) & (5) & (11) \\
\hline \multirow{2}{*}{ Idade do filho mais velho } & 14 & 13 & 9 & 14 \\
\hline & (8) & (9) & (7) & (11) \\
\hline \multirow{2}{*}{$\%$ Mulheres com filhos de 0 a 5 anos } & 0,39 & 0,44 & 0,63 & 0,43 \\
\hline & $(0,49)$ & $(0,50)$ & $(0,48)$ & $(0,49)$ \\
\hline \multirow{2}{*}{$\begin{array}{l}\% \text { Mulheres com filhos de } 6 \text { a } 10 \\
\text { anos }\end{array}$} & 0,46 & 0,43 & 0,47 & 0,34 \\
\hline & $(0,50)$ & $(0,49)$ & $(0,50)$ & $(0,47)$ \\
\hline \multirow{2}{*}{$\begin{array}{l}\% \text { Mulheres com filhos de } 11 \text { a } 14 \\
\text { anos }\end{array}$} & 0,45 & 0,31 & 0,28 & 0,23 \\
\hline & $(0,50)$ & $(0,46)$ & $(0,45)$ & $(0,42)$ \\
\hline \multirow{2}{*}{$\begin{array}{l}\text { \% Mulheres com filhos de } 15 \text { a } 18 \\
\text { anos }\end{array}$} & 0,33 & 0,24 & 0,19 & 0,21 \\
\hline & $(0,47)$ & $(0,43)$ & $(0,39)$ & $(0,41)$ \\
\hline \multirow{2}{*}{$\begin{array}{l}\% \text { Mulheres com filhos de } 19 \text { anos ou } \\
\text { mais }\end{array}$} & 0,23 & 0,24 & 0,10 & 0,29 \\
\hline & $(0,42)$ & $(0,43)$ & $(0,31)$ & $(0,45)$ \\
\hline \multirow{2}{*}{$\%$ Mulheres que trabalham } & 0,50 & 0,48 & 0,32 & 0,42 \\
\hline & $(0,50)$ & $(0,50)$ & $(0,47)$ & $(0,49)$ \\
\hline \multirow{2}{*}{$\begin{array}{l}\text { Jornada de trabalho mensal (em } \\
\text { horas) }\end{array}$} & 33 & 36 & 33 & 37 \\
\hline & (15) & (14) & $(15)$ & (14) \\
\hline \multirow{2}{*}{ Salário do trabalho principal (em R\$) } & 150,6 & 228,6 & 123,7 & 235,6 \\
\hline & $(165,5)$ & $(258,8)$ & $(121,2)$ & $(168,1)$ \\
\hline \multirow{2}{*}{ Renda domiciliar per capita (em R\$) } & 115,2 & 150,8 & 60,8 & 145,9 \\
\hline & $(92,9)$ & $(167,0)$ & $(29,9)$ & $(67,0)$ \\
\hline \multirow{2}{*}{$\begin{array}{l}\text { Renda domiciliar per capita exceto a } \\
\text { renda da mãe (em } \mathrm{R} \$)\end{array}$} & 96,8 & 121,4 & 50,7 & 118,7 \\
\hline & $(85,3)$ & $(140,8)$ & $(33,1)$ & $(68,4)$ \\
\hline \multirow{2}{*}{$\begin{array}{l}\text { Número de observações } \\
\text { (amostra e população) }\end{array}$} & 15.245 & 2.532 & 8.456 & 31.414 \\
\hline & 6.624 .403 & 1.179 .225 & 3.524 .504 & 13.850 .213 \\
\hline
\end{tabular}

Notas: Desvio padrão entre parênteses; Grupo avaliado: mães inscritas no PBF, que recebem transferência em dinheiro; Grupo de controle 1: mães inscritas no $\mathrm{PBF}$, que não recebem transferência em dinheiro; Grupo de controle 2: mães não inscritas no PBF, que pertencem ao público-alvo; Grupo de controle 3: mães não beneficiárias do $\mathrm{PBF}$, com renda familiar per capita igual ou inferior a $\mathrm{R} \$ 260,00$.

Fonte: PNAD (2004). 
A renda domiciliar per capita das mães do grupo de controle 1 é um pouco maior do que a do grupo avaliado ( $\mathrm{R} \$ 115,2$ e $\mathrm{R} \$ 150,8)$. De qualquer forma, para ambos os grupos, a renda domiciliar per capita média excede a renda de corte estabelecida pelo programa como critério de elegibilidade (R\$ 100,00). ${ }^{25}$ A renda domiciliar per capita do grupo de controle 3 é de $\mathrm{R} \$ 145,9$.

Em comparação com as mães do grupo avaliado, as mães do grupo de controle 2 apresentam renda familiar per capita menor, já que neste grupo estão apenas as mães que atendem aos critérios de seleção da política e são, portanto, pobres ou extremamente pobres. Para os quatro grupos, a renda auferida pelos demais membros da família (renda domiciliar exceto a renda da mãe) corresponde a $80 \%$ da renda total. Isso significa que a renda do trabalho das mães beneficiárias e não beneficiárias responde por cerca de $20 \%$ do orçamento da família.

As descrições mostram que os grupos de controle são bastante semelhantes ao grupo avaliado quanto às características observáveis. A próxima seção apresenta o procedimento econométrico adotado para tornar o grupo avaliado ainda mais semelhante a cada um dos grupos de controle e apresenta os modelos utilizados na estimação do impacto da concessão do benefício do PBF sobre as decisões de participação no mercado e jornada de trabalho.

\section{Procedimentos econométricos}

A partir dos três grupos de controle selecionados, procedeu-se ao propensity score matching para encontrar mães não beneficiárias com o máximo possível de semelhança em características observáveis às mães beneficiárias. $\mathrm{O}$ propensity score matching realiza o 'pareamento' entre as observações do grupo avaliado e do grupo de controle utilizando a probabilidade de participação no programa, estimada a partir de características observáveis. ${ }^{26}$

Para definir o propensity score (probabilidade de inclusão no PBF), estimou-se o seguinte modelo probit: $:^{27}$

$$
B F=\alpha+\sum_{i=3}^{9} \beta_{i} X_{i}+\sum_{j=10}^{21} \beta_{j} Z_{j}+\varepsilon
$$

em que:

$B F$ : variável dummy que indica a participação no PBF;

(25) Isso mostra que existe vazamento na distribuição dos recursos do programa. De qualquer forma, Tavares et al. (2008) ressaltam que as famílias não elegíveis incluídas no programa ainda são de baixa renda.

(26) Ver Rosenbaum e Rubin (1983).

(27) Neste trabalho, todas as estimações utilizaram os pesos da PNAD para a expansão da amostra. 
$\checkmark \quad X_{i}$ : vetor de características pessoais (idade, idade ao quadrado, anos de estudos, número de filhos de 0 a 15 anos; dummy para cor branca, dummy para mulheres com cônjuge; dummy para mulheres chefes da família);

$\checkmark Z_{i}$ : vetor de características do domicílio (dummies para macrorregiões; dummies para região urbana; dummy para região metropolitana; dummies para casa própria; acesso à água encanada; rede coletora de lixo; rede de esgoto; energia elétrica e densidade morador-cômodo).

Depois de prever o propensity score, permitiu-se que cada observação do grupo avaliado fosse pareada a apenas uma observação do grupo de controle (pareamento sem reposição), que fosse a mais próxima em probabilidade de participação no programa (não se diferenciassem em mais de 0,0001). O mesmo procedimento foi realizado para o pareamento do grupo avaliado a cada um dos três grupos de controle.

Em todas as amostras, a interpretação das variáveis que preveem a probabilidade de participação no programa foi intuitiva: ${ }^{28}$ a idade associa-se a maiores chances de a mãe ser beneficiária, mas de forma decrescente, enquanto o nível de escolaridade associa-se à menor probabilidade de ser beneficiária do programa, assim como o fato de a mãe ser de cor branca e de possuir cônjuge. Curiosamente, mães chefes da família têm menos chances de ser incluídas na política. Como esperado, quanto maior o número de filhos com idade entre 0 e 15 anos, maior a probabilidade de a mãe estar incluída na política. $\mathrm{O}$ maior acesso à infraestrutura também está relacionado a menores chances de inclusão no PBF; a exceção é o acesso à energia elétrica. $\mathrm{O}$ fato de residir em regiões urbanas (metropolitanas) aumenta (reduz) as chances de estar entre as beneficiárias.

Como forma de checar a qualidade do matching, estimou-se o modelo probit da equação 1, mas apenas para as amostras pareadas. Se o matching foi 'benfeito', ou seja, se o grupo avaliado e o grupo de controle são bastante semelhantes quanto às variáveis observáveis, as covariadas não deveriam explicar a probabilidade de participação no programa. Desse modo, se as observações pareadas dos grupos avaliado e de controle forem de fato parecidas, as variáveis explicativas deveriam ser conjuntamente não significantes no modelo probit estimado para as amostras pareadas. Isso pode ser verificado por meio do teste $\mathrm{F}$ de existência da regressão, cuja hipótese nula considera que todos os coeficientes do modelo são nulos. A Tabela 2 a seguir apresenta o número de observações de cada amostra pareada e o p-valor associado ao teste.

(28) Os resultados foram omitidos por questões de espaço. 
Efeito do Programa Bolsa Família sobre a oferta de trabalho das mães

Tabela 2

Número de observações e qualidade do matching

\begin{tabular}{l|c|c|c}
\hline & Controle 1 & Controle 2 & Controle 3 \\
\hline $\mathrm{N}^{\mathrm{o}}$ observações & 4.998 & 5.684 & 25.480 \\
\cline { 2 - 4 } (amostra e população) & 2.274 .364 & 2.430 .700 & 11.009 .912 \\
\hline $\mathrm{p}$-valor & 0,96 & 0,36 & 0,26 \\
\hline
\end{tabular}

Notas: O número de observações refere-se às amostras pareadas; Grupo avaliado: mães inscritas no PBF, que recebem transferência em dinheiro; Grupo de controle 1: mães inscritas no PBF, que não recebem transferência em dinheiro; Grupo de controle 2: mães não inscritas no PBF, que pertencem ao público-alvo; Grupo de controle 3: mães não beneficiárias do $\mathrm{PBF}$, com renda familiar per capita igual ou inferior a $\mathrm{R} \$ 260,00$.

Fonte: PNAD (2004).

Nos três casos (pareamento do grupo avaliado com os grupos de controle 1, 2 e 3), não se pode rejeitar a hipótese nula, ou seja, o teste sugere que as variáveis explicativas não são conjuntamente significantes quando o modelo é estimado a partir das amostras pareadas. Isso significa que, depois de realizado o matching, não há diferenças significativas entre o grupo avaliado e os grupos de controle que se relacionem à participação no programa e que de fato as mães beneficiárias e não beneficiárias das amostras pareadas são bastante semelhantes.

Depois de realizado o matching, estimou-se, para cada uma das amostras pareadas, os impactos do PBF sobre a participação e a jornada de trabalho.

Para o caso da jornada de trabalho, deve-se notar que existe um problema de censura dos dados. Isso porque a jornada só é observada para as mães que participam do mercado de trabalho, ou seja, que decidiram trabalhar e encontraram um emprego. Para as mães que não trabalham, a jornada observada é zero. Desse modo, para estas últimas, a jornada de trabalho potencial não é conhecida. ${ }^{29}$ Assim, a amostra de mulheres que apresentam jornada de trabalho positiva é uma amostra selecionada, que depende da participação no mercado de trabalho. Então, utilizar essa amostra para estimar o impacto do PBF sobre a jornada de trabalho geraria conclusões equivocadas, uma vez que omitiria as variáveis que determinam a participação da mulher no mercado de trabalho. ${ }^{30}$ Por esse motivo, o correto é utilizar um procedimento que tente eliminar esse viés, conhecido como modelo de Heckman. Esse método consiste em estimar o modelo para a jornada de trabalho (equação estrutural) a partir de um modelo para a participação no mercado (equação de seleção), utilizando toda a amostra de mães (que trabalham e

(29) Para as mulheres que não trabalham porque decidiram não trabalhar, a jornada de trabalho é, de fato, nula. Para as mulheres que não trabalham porque não conseguiram um emprego, a quantidade de horas que elas decidiriam ofertar se estivessem empregadas seria positiva, mas não é conhecida. Do total de mães da amostra, 50\% trabalham e informam jornadas de trabalho positivas. Dentre as que não trabalham, $18 \%$ estão desempregadas, ou seja, informam jornada de trabalho nula, mas que seria positiva caso estivessem trabalhando.

(30) Os coeficientes seriam viesados.

Economia e Sociedade, Campinas, v. 19, n. 3 (40), p. 613-635, dez. 2010. 
que não trabalham), de modo a considerar também as variáveis que afetam a decisão da mulher de trabalhar, que estariam omitidas (Heckman, 1979).

Assim, para medir o impacto do PBF sobre a participação no mercado de trabalho, estimou-se um modelo probit descrito pela equação 2:

$$
y_{1}=\alpha+\beta_{1} B F+\beta_{2} \text { valor } B F+\sum_{i=3}^{20} \beta_{i} X_{i}+\sum_{j=21}^{26} \beta_{j} Z_{j}+\varepsilon^{(2)}
$$

Em seguida, estimou-se um modelo de mínimos quadrados ordinários descrito pela equação 3, para medir o impacto do PBF sobre a jornada de trabalho.

$$
y_{2}=\alpha+\beta_{1} B F+\beta_{2} \text { valor } B F+\sum_{i=3}^{20} \beta_{i} X_{i}+\beta_{21} \text { urbana }+\varepsilon \text { (3) }
$$

em que:

- $\mathrm{y}_{1}$ é a dummy que indica a participação no mercado de trabalho.

$-\mathrm{y}_{2}$ é a jornada de trabalho semanal.

- BF é a dummy que indica a participação no PBF.

- valorBF é a variável que indica o valor da transferência do benefício.

- X é composto por características pessoais:

$\checkmark$ anos de estudos;

$\checkmark$ idade e idade ao quadrado;

$\checkmark$ dummy para cor branca;

$\checkmark$ dummy para mulheres com cônjuge;

$\checkmark$ dummy para mulheres chefes da família;

$\checkmark$ dummies para o número de filhos de $(0$ a $5 ; 6$ a $10 ; 11$ a $14 ; 15$ a 18 e 19 anos ou mais);

$\checkmark$ renda domiciliar per capita, excluindo os rendimentos do trabalho da mãe.

- Z é composto por características de local de moradia:

$\checkmark$ dummies para as macrorregiões (Sudeste como default);

$\checkmark$ dummy para a região urbana;

$\checkmark$ dummy para a região metropolitana.

Note que a equação 1 é utilizada para estimar os efeitos do PBF sobre a participação e também serve como equação de seleção para o método de Heckman que estima os efeitos do PBF sobre a jornada. Em geral, incluem-se na equação de seleção variáveis que sirvam como instrumentos para a estimação, ou seja, que se relacionem com a variável que determina a seleção (participação), mas não se 
relacionem com a variável dependente de interesse (jornada). Então, considerou-se que a macrorregião e o porte do município em que a mãe reside influenciam a empregabilidade, de modo a afetar a participação no mercado, mas não influenciam a quantidade de horas trabalhadas, ou seja, a jornada de trabalho. Não se faz a mesma hipótese com relação às regiões urbana e rural, ou seja, considerase que a zona de moradia influencia tanto a participação quanto a jornada de trabalho.

Os resultados dos impactos do PBF sobre as decisões de engajamento no mercado de trabalho das mães são descritos na próxima seção.

\section{Resultados}

A Tabela 3 apresenta os impactos do PBF sobre a participação e a jornada de trabalho das mães, estimados para as amostras não pareadas (sem matching) e pareadas (com matching). Os modelos completos estão no Anexo.

Tabela 3

Impacto do Bolsa Família sobre a oferta de trabalho

\begin{tabular}{|c|c|c|c|c|}
\hline & & \multicolumn{3}{|c|}{ Participação } \\
\hline & & Grupo de controle 1 & Grupo de controle 2 & Grupo de controle 3 \\
\hline \multirow{4}{*}{ च } & \multirow{2}{*}{$\mathrm{BF}$} & 0,0047 & 0,1900 & 0,0320 \\
\hline & & 0,00 & 0,00 & 0,00 \\
\hline & \multirow{2}{*}{ valor do BF } & $-0,0002$ & $-0,0003$ & $-0,0003$ \\
\hline & & 0,00 & 0,00 & 0,00 \\
\hline \multirow{6}{*}{ 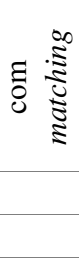 } & \multirow{2}{*}{$\mathrm{BF}$} & 0,0145 & 0,2080 & 0,0380 \\
\hline & & 0,00 & 0,00 & 0,00 \\
\hline & \multirow{2}{*}{ valor do $\mathrm{BF}$} & $-0,0002$ & $-0,0004$ & $-0,0003$ \\
\hline & & 0,00 & 0,00 & 0,00 \\
\hline & & \multicolumn{3}{|c|}{ Jornada } \\
\hline & & Grupo de controle 1 & Grupo de controle 2 & Grupo de controle 3 \\
\hline \multirow{4}{*}{ 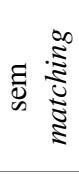 } & \multirow{2}{*}{$\mathrm{BF}$} & 0,3967 & 0,1923 & 1,4426 \\
\hline & & 0,00 & 0,00 & 0,00 \\
\hline & \multirow{2}{*}{ valor do $\mathrm{BF}$} & $-0,0141$ & $-0,0146$ & $-0,0135$ \\
\hline & & 0,00 & 0,00 & 0,00 \\
\hline \multirow{4}{*}{ ¿ } & \multirow{2}{*}{$\mathrm{BF}$} & 0,4223 & 0,7356 & 1,1720 \\
\hline & & 0,00 & 0,00 & 0,00 \\
\hline & \multirow{2}{*}{ valor do $\mathrm{BF}$} & $-0,0105$ & $-0,0079$ & $-0,0127$ \\
\hline & & 0,00 & 0,00 & 0,00 \\
\hline
\end{tabular}

Notas: P-valor entre parênteses. Os coeficientes de participação referem-se aos efeitos marginais; Grupo avaliado: mães inscritas no PBF, que recebem transferência em dinheiro; Grupo de controle 1: mães inscritas no PBF, que não recebem transferência em dinheiro; Grupo de controle 2: mães não inscritas no $\mathrm{PBF}$, que pertencem ao público-alvo; Grupo de controle 3: mães não beneficiárias do PBF, com renda familiar per capita igual ou inferior a $\mathrm{R} \$ 260,00$.

Fonte: PNAD (2004). 
Nos dois modelos de oferta de trabalho, os coeficientes das características pessoais das mães têm o sinal esperado: o nível de escolaridade e a idade elevam a participação no mercado e a jornada de trabalho, assim como o fato de a mãe ser de cor branca ou chefe da família. No entanto, mães com cônjuge trabalham menos. O número de filhos pequenos ( 0 a 10 anos) afeta negativamente o engajamento da mãe no mercado de trabalho, tanto por sua menor participação quanto por menores jornadas. Quanto maior a renda per capita da família, menor a participação das mães no mercado de trabalho e maiores são suas jornadas. Finalmente, o fato de residir em regiões metropolitanas reduz a probabilidade de participação no mercado, assim como o fato de residir em regiões urbanas. Entretanto, mães que moram nas cidades têm jornadas de trabalho maiores.

Quando se considera a participação no mercado de trabalho como variável dependente, os coeficientes da dummy que indica a participação no PBF são significantes e positivos, na comparação com qualquer grupo de controle analisado. Isso indica que o fato de a família ser beneficiária do PBF parece elevar a participação das mães no mercado de trabalho. ${ }^{31}$

Os efeitos do PBF sobre a jornada de trabalho são semelhantes: todos os coeficientes são positivos e significantes, indicando que o fato de a família receber o aditamento do programa também aumenta a quantidade de trabalho ofertada pelas mães.

Quando se avalia o impacto de cada real transferido sobre as decisões de trabalho das mães beneficiárias, nota-se que os coeficientes da variável que indica o valor do benefício recebido são significantes e negativos, o que implica que tanto a participação no mercado quanto a jornada de trabalho das mães beneficiárias diminuem à medida que o valor da transferência aumenta.

Esses resultados parecem contradizer o mito do 'efeito-preguiça'. Em outras palavras, considerando o valor médio atualmente transferido às famílias beneficiárias, o efeito-substituição parece dominar o efeito-renda na determinação do impacto do programa sobre as decisões de trabalho das mães. Uma explicação para o efeito positivo da participação no programa sobre o engajamento das mães no mercado de trabalho pode residir no fato de que seus filhos, que agora precisam frequentar a escola, reduziram sua oferta de trabalho. Desse modo, a mãe precisa trabalhar mais para compensar a perda da renda do trabalho no domicílio. Mesmo que seus filhos não trabalhassem, o simples fato de passarem a frequentar a escola poderia reduzir o tempo que ficam em casa e que, portanto, necessitam de cuidados da mãe. Ou seja, as mães passariam a dispor de mais tempo para o trabalho.

(31) Os efeitos são heterogêneos, variam de 1,5\% a $21 \%$. 
Outra explicação para o efeito positivo do recebimento do benefício sobre a oferta de trabalho é dada pela literatura que trata do estigma associado a políticas públicas. O 'efeito estigma' corresponderia à discriminação sofrida ou autoimposta pelo indivíduo que participa do PBF pelo fato de ser beneficiário. $\mathrm{O}$ indivíduo 'estigmatizado' adotaria um comportamento no sentido de reduzir sua dependência em relação à transferência, por exemplo, procurando emprego ou trabalhando mais.

Assim, parte do efeito positivo do recebimento do benefício do programa sobre a oferta de trabalho das mães pode se dever à atitude destas perante o estigma de participar do programa. Esse argumento é corroborado por Mattos e Ponczek (2007), que encontram um resultado positivo do 'efeito estigma' sobre a procura por novos empregos e a redução do desemprego para membros de famílias beneficiárias do $\mathrm{PBF}^{32}$

Por um lado, o efeito negativo do valor da transferência sobre a oferta de trabalho pode sugerir que aumentos no valor do benefício podem fazer com que o efeito-renda seja tão grande que supere o efeito-substituição a tal ponto que o incentivo adverso ao trabalho apareça. Ou seja, se o valor transferido às famílias se elevar muito, pode haver algum benefício para as mães em reduzir sua oferta de trabalho, por exemplo, para gozar de mais tempo para se dedicar aos filhos e às atividades domésticas. Assim, em termos de políticas públicas, pode-se pensar que deve existir um valor ótimo para a transferência. Por outro lado, maiores valores da transferência também poderiam elevar o estigma sobre os beneficiários. Assim, o efeito de aumentos no valor do aditamento do programa sobre as decisões de trabalho é uma questão empírica que ainda precisa ser investigada, mas que foge ao escopo deste trabalho.

\section{Conclusões}

Este artigo propôs-se a investigar a existência de possíveis incentivos adversos do PBF com relação às decisões relacionadas à oferta de trabalho (participação no mercado e jornada) das mães beneficiárias pelo programa, questão que ainda representa uma lacuna nesta literatura.

Como a seleção ao programa é não aleatória, pode-se supor que as características que determinam a participação na política podem estar associadas a decisões de engajamento no mercado de trabalho (participação e jornada), o que impede a simples comparação do comportamento de mães beneficiárias e não

(32) Os autores utilizam dados de pesquisa domiciliar realizada em 2005 pelo Ministério do Desenvolvimento Social e Combate à Fome com os beneficiários do PBF. Nesta pesquisa, existe uma pergunta que investiga o constrangimento do beneficiário por receber a transferência do programa, que é utilizada para definir a existência de estigma.

Economia e Sociedade, Campinas, v. 19, n. 3 (40), p. 613-635, dez. 2010. 
beneficiárias no que tange às suas preferências por trabalho. O esforço empregado neste artigo foi o de selecionar, a partir de grupos de controle previamente estabelecidos, mães não beneficiárias que se assemelhassem às beneficiárias em termos dos determinantes da participação no programa, de modo que se pudesse simular a situação em que a seleção para participação no programa fosse aleatória.

Para isso, empregou-se o método de propensity score matching, a fim de encontrar pares para as observações do grupo avaliado, composto por mães que declararam participar e receber transferência em dinheiro do PBF. Consideraramse três grupos de controle: 1) mães inscritas no PBF que não recebem transferência em dinheiro do programa; 2) mães não beneficiárias que pertencem ao públicoalvo do programa; 3) mães não beneficiárias que residem em domicílios cuja renda per capita é menor ou igual a $\mathrm{R} \$ 260,00$. Para estimar os efeitos sobre a participação no mercado e a jornada de trabalho, utilizaram-se os modelos probit $\mathrm{e}$ de Heckman.

Os resultados mostram que, embora exista um efeito-renda negativo sobre as decisões de trabalho das mães, expresso pelo coeficiente associado ao valor do benefício, ele não parece ser suficiente para gerar o chamado 'efeito-preguiça', ou seja, um incentivo adverso caracterizado pela redução da oferta ou da jornada de trabalho das mães beneficiárias do PBF. Isso porque o efeito da participação no programa sobre as decisões de trabalho das mães é, na verdade, positivo. A explicação para esse resultado pode advir do efeito-substituição, caracterizado pelo aumento da oferta de trabalho das mães como consequência do aumento da frequência escolar dos filhos e, portanto, da redução do trabalho infantil.

Além disso, pode-se supor que o simples fato de deixar suas crianças na escola implica maior tempo disponível das mães para o trabalho, o que serve de mais um argumento para o efeito positivo do programa sobre a oferta de trabalho. Finalmente, também se pode considerar que o recebimento do benefício do programa estimula o aumento da oferta de trabalho das mães como resposta ao estigma de participar do programa.

\section{Bibliografia}

ANUATTI-NETO, F.; FERNANDES, R.; PAZELLO, E. T. Poverty alleviation policies: the problem of targeting when income is not observed. Ribeirão Preto: FEARP, 2001. (Texto para discussão, 17).

BOURGUIGNON, F.; FERREIRA, F. H. G.; LEITE, P. G. Ex-ante evaluation of conditional cash transfer programs: the case of bolsa escola. Michigan, 2002. (Working Paper, 516).

CARDOSO, E.; SOUZA, A. P. The impact of cash transfers on child labor and school attendance in Brazil. Vanderbilt, 2004. (Working Paper 04-W07). 
CENTRO DE DESENVOLVIMENTO E PLANEJAMENTO REGIONAL (Cedeplar). Projeto de avaliação do impacto do Programa Bolsa Família - relatório analítico final. Belo Horizonte, 2006. Mimeografado.

CHEIN, F.; ANDRADE, M. V.; RIBAS, R. P. Políticas de transferência de renda e condição nutricional de crianças: uma avaliação do Bolsa Família. Belo Horizonte [s.n.], 2006. Mimeografado.

FERRO, A. R.; KASSOUF, A. L. Avaliação do impacto do Programa Bolsa-Escola sobre o trabalho infantil no Brasil. Pesquisa e Planejamento Econômico, v. 35, n. 3, p. 417-444, 2005.

FOGUEL, M.; BARROS, R. P. The effects of conditional cash transfer Programmes on Adult Labour Supply: an empirical analysis using a time-series-cross-section. In: ENCONTRO NACIONAL DE ECONOMIA, 33, Salvador, 2008. Anais...

HECKMAN, J. J. Sample selection bias as a specification error. Econometrica, 47, p. 153$161,1979$.

INSTITUTO DE PESQUISA ECONÔMICA APLICADA. Desigualdade de renda no Brasil: uma análise da queda recente. Brasília: Ipea, 2007.

MARQUES, R. M. A importância do Bolsa Família nos municípios brasileiros. Caderno de Estudos Desenvolvimento Social em Debate, Brasília, MDS, n. 1, 2005.

; LEITE, M. G.; MENDES, A.; FERREIRA, M. R. J. Discutindo o papel do Programa Bolsa Família na decisão das eleições presidenciais brasileiras de 2006. Revista de Economia Política, São Paulo, v. 29, n. 1, jan./mar. 2009.

MATTOS, E.; PONCZEK, V. O efeito do estigma sobre os beneficiários de programas de transferência de renda no Brasil. São Paulo, 2007. (Working paper). Disponível em: http://www.eesp.fgv.br/publicacao_detalhe.php?idPublicacao=481. Acesso em: 21 jul. 2008.

MDS. Sumário Executivo de Avaliação de Impacto do Programa Bolsa Família. Brasília, 2007. Disponível em: http://www.mds.gov.br/institucional/secretarias/secretaria-deavaliacao-e-gestao-da-informacao-sagi/arquivo-sagi/pesquisas.

MEDEIROS, M.; BRITTO, T.; SOARES, F. Programas focalizados de transferência de renda no Brasil: contribuições para o debate. Brasília, 2007. (Texto para discussão, 1283).

PAZELLO, E.; FERNANDES, R. A maternidade e a mulher no mercado de trabalho: diferença de comportamento entre mulheres que têm e que não têm filhos. In: ENCONTRO NACIONAL DE ECONOMIA, 32, João Pessoa, 2004. Anais...

PEDROZO, E. Uma avaliação ex-ante dos impactos do Bolsa Família na redução do trabalho infantil. In: ENCONTRO NACIONAL DE ECONOMIA, 32, Recife, 2007. Anaisi...

RESENDE. Avaliando resultados de um programa de transferência de renda: o impacto do Bolsa-Escola sobre os gastos das famílias brasileiras, 2006. 115f. Dissertação (Mestrado em Economia) - Faculdade de Ciências Econômicas da Universidade Federal de Minas Gerais, Belo Horizonte, 2006

Economia e Sociedade, Campinas, v. 19, n. 3 (40), p. 613-635, dez. 2010. 
Priscilla Albuquerque Tavares

ROSEMBAUM, P. R.; RUBIN, D. B. The central role of the propensity score in observational studies for casual effects. Biometrika, 70, p. 41-55, 1983.

SCORZAFAVE, L. G.; MENEZES-FILHO, N. A. Participação feminina no mercado de trabalho brasileiro: evolução e determinantes. Pesquisa e Planejamento Econômico, Rio de Janeiro, v. 31, n. 3, p. 441-478, dez. 2001.

SOARES, F.; SOARES, S.; MEDEIROS, M.; OSÓRIO, R. Programas de transferência de renda no Brasil: impactos sobre a desigualdade. Brasília: Ipea, 2006. (Texto para Discussão, n. 1228).

SOARES, S.; IZAKI, R. S. A participação feminina no mercado de trabalho. Rio de Janeiro: Ipea, 2002. (Texto para Discussão, n. 293).

; RIBAS, R. P.; SOARES, F. V. Focalização e cobertura do Programa Bolsa Família: qual o significado dos 11 milhões de famílias? In: ENCONTRO NACIONAL DE ECONOMIA, 33, Salvador, 2008. Anais...

TAVARES, P. A.; PAZELLO, E. T.; FERNANDES, R.; CAMELO, R. S. Uma avaliação do Programa Bolsa Família: focalização e impacto na distribuição de renda e pobreza. Ribeirão Preto [s.n.], 2008. Mimeografado. 


\section{Anexo}

Tabela A.1

Efeitos marginais dos modelos probit para participação no mercado de trabalho

\begin{tabular}{|c|c|c|c|}
\hline & Grupo de controle 1 & Grupo de controle 2 & Grupo de controle 3 \\
\hline \multirow{2}{*}{ Anos de escolaridade } & 0,0263 & 0,0125 & 0,0203 \\
\hline & $(0,00)$ & $(0,00)$ & $(0,00)$ \\
\hline \multirow{2}{*}{ Idade } & 0,0489 & 0,0392 & 0,0441 \\
\hline & $(0,00)$ & $(0,00)$ & $(0,00)$ \\
\hline \multirow{2}{*}{ Idade ao quadrado } & $-0,0006$ & $-0,0005$ & $-0,0006$ \\
\hline & $(0,00)$ & $(0,00)$ & $(0,00)$ \\
\hline \multirow{2}{*}{ Cor branca } & 0,0213 & $-0,0044$ & 0,0069 \\
\hline & $(0,00)$ & $(0,00)$ & $(0,00)$ \\
\hline \multirow{2}{*}{ Mãe chefe } & 0,0590 & 0,0779 & 0,0491 \\
\hline & $(0,00)$ & $(0,00)$ & $(0,00)$ \\
\hline \multirow{2}{*}{ Mãe com cônjuge } & $-0,0554$ & $-0,1074$ & $-0,0825$ \\
\hline & $(0,00)$ & $(0,00)$ & $(0,00)$ \\
\hline \multirow{2}{*}{ Norte } & 0,0538 & 0,0123 & 0,0137 \\
\hline & $(0,00)$ & $(0,00)$ & $(0,00)$ \\
\hline \multirow{2}{*}{ Nordeste } & $-0,0349$ & 0,0504 & $-0,0033$ \\
\hline & $(0,00)$ & $(0,00)$ & $(0,00)$ \\
\hline \multirow{2}{*}{ Sul } & 0,0149 & 0,1462 & 0,0908 \\
\hline & $(0,00)$ & $(0,00)$ & $(0,00)$ \\
\hline \multirow{2}{*}{ Centro-oeste } & $-0,0169$ & 0,0516 & 0,0100 \\
\hline & $(0,00)$ & $(0,00)$ & $(0,00)$ \\
\hline \multirow{2}{*}{ Região metropolitana } & $-0,0613$ & $-0,0972$ & $-0,0553$ \\
\hline & $(0,00)$ & $(0,00)$ & $(0,00)$ \\
\hline \multirow{2}{*}{ Região urbana } & $-0,1162$ & $-0,1587$ & $-0,1588$ \\
\hline & $(0,00)$ & $(0,00)$ & $(0,00)$ \\
\hline \multirow{2}{*}{$\mathrm{N}^{\mathrm{o}}$ de filhos de 0 a 5 anos } & $-0,0928$ & $-0,0518$ & $-0,0808$ \\
\hline & $(0,00)$ & $(0,00)$ & $(0,00)$ \\
\hline \multirow{2}{*}{$\mathrm{N}^{\mathrm{o}}$ de filhos de 6 a 10 anos } & $-0,0126$ & 0,0014 & $-0,0175$ \\
\hline & $(0,00)$ & $(0,00)$ & $(0,00)$ \\
\hline \multirow{2}{*}{$\mathrm{N}^{\circ}$ de filhos de 11 a 14 anos } & $-0,0099$ & 0,0300 & 0,0053 \\
\hline & $(0,00)$ & $(0,00)$ & $(0,00)$ \\
\hline \multirow{2}{*}{$\mathrm{N}^{\mathrm{o}}$ de filhos de 15 a 18 anos } & 0,0083 & 0,0318 & 0,0121 \\
\hline & $(0,00)$ & $(0,00)$ & $(0,00)$ \\
\hline \multirow{2}{*}{$\begin{array}{l}\mathrm{N}^{\circ} \text { de filhos de } 19 \text { anos ou } \\
\text { mais }\end{array}$} & 0,0146 & 0,0115 & $-0,0042$ \\
\hline & $(0,00)$ & $(0,00)$ & $(0,00)$ \\
\hline \multirow{2}{*}{$\begin{array}{l}\text { Renda domiciliar per capita } \\
\text { exceto a renda da mãe }\end{array}$} & $-0,0004$ & $-0,0009$ & $-0,0011$ \\
\hline & $(0,00)$ & $(0,00)$ & $(0,00)$ \\
\hline \multirow{2}{*}{$\mathrm{BF}$} & 0,0145 & 0,2080 & 0,0380 \\
\hline & $(0,00)$ & $(0,00)$ & $(0,00)$ \\
\hline \multirow{2}{*}{ Valor do BF } & $-0,0002$ & $-0,0004$ & $-0,0003$ \\
\hline & $(0,00)$ & $(0,00)$ & $(0,00)$ \\
\hline
\end{tabular}

Notas: p-valor entre parênteses; Grupo avaliado: mães inscritas no PBF, que recebem transferência em dinheiro; Grupo de controle 1: mães inscritas no PBF, que não recebem transferência em dinheiro; Grupo de controle 2: mães não inscritas no PBF, que pertencem ao público-alvo; Grupo de controle 3: mães não beneficiárias do PBF, com renda familiar per capita igual ou inferior a $\mathrm{R} \$ 260,00$.

Fonte: PNAD (2004). 
Tabela A.2

Coeficientes do modelo de Heckman

\begin{tabular}{|c|c|c|c|}
\hline \multicolumn{4}{|c|}{ Equação Estrutural para a jornada de trabalho } \\
\hline & Grupo de controle 1 & Grupo de controle 2 & Grupo de controle 3 \\
\hline \multirow{2}{*}{ Anos de escolaridade } & 0,0502 & 0,1457 & $-0,0386$ \\
\hline & $(0,00)$ & $(0,00)$ & $(0,59)$ \\
\hline \multirow{2}{*}{ Idade } & $-0,2468$ & 0,1949 & 0,1971 \\
\hline & $(0,00)$ & $(0,00)$ & $(0,27)$ \\
\hline \multirow{2}{*}{ Idade ao quadrado } & 0,0015 & $-0,0034$ & $-0,0044$ \\
\hline & $(0,00)$ & $(0,00)$ & $(0,05)$ \\
\hline \multirow{2}{*}{ Cor branca } & 1,1723 & $-1,0101$ & 0,3683 \\
\hline & $(0,00)$ & $(0,00)$ & $(0,19)$ \\
\hline \multirow{2}{*}{ Mãe chefe } & 2,2029 & $-1,0555$ & 0,7883 \\
\hline & $(0,00)$ & $(0,00)$ & $(0,08)$ \\
\hline \multirow{2}{*}{ Mãe com cônjuge } & $-3,1188$ & $-4,1276$ & $-2,6794$ \\
\hline & $(0,00)$ & $(0,00)$ & $(0,00)$ \\
\hline \multirow{2}{*}{ Região urbana } & 4,4940 & 6,9496 & 6,0795 \\
\hline & $(0,00)$ & $(0,00)$ & $(0,00)$ \\
\hline \multirow{2}{*}{$\mathrm{N}^{\mathrm{o}}$ de filhos de 0 a 5 anos } & $-0,2696$ & $-0,5983$ & $-0,8040$ \\
\hline & $(0,00)$ & $(0,00)$ & $(0,01)$ \\
\hline \multirow{2}{*}{$\mathrm{N}^{\circ}$ de filhos de 6 a 10 anos } & $-0,2023$ & $-0,7430$ & $-0,3952$ \\
\hline & $(0,00)$ & $(0,00)$ & $(0,04)$ \\
\hline \multirow{2}{*}{$\mathrm{N}^{\circ}$ de filhos de 11 a 14 anos } & 0,7785 & 0,2051 & 0,3368 \\
\hline & $(0,00)$ & $(0,00)$ & $(0,10)$ \\
\hline \multirow{2}{*}{$\mathrm{N}^{\circ}$ de filhos de 15 a 18 anos } & 0,7877 & $-0,2335$ & 0,2109 \\
\hline & $(0,00)$ & $(0,00)$ & $(0,33)$ \\
\hline \multirow{2}{*}{$\mathrm{N}^{\circ}$ de filhos de 19 anos ou mais } & 0,5335 & $-0,8151$ & $-0,1377$ \\
\hline & $(0,00)$ & $(0,00)$ & $(0,53)$ \\
\hline \multirow{2}{*}{$\begin{array}{l}\text { Renda domiciliar per capita } \\
\text { exceto a renda da mãe }\end{array}$} & 0,0018 & 0,0097 & 0,0031 \\
\hline & $(0,00)$ & $(0,00)$ & $(0,41)$ \\
\hline \multirow{2}{*}{$\mathrm{BF}$} & 0,4223 & 0,7356 & 1,1720 \\
\hline & $(0,00)$ & $(0,00)$ & $(0,00)$ \\
\hline \multirow{2}{*}{ Valor do BF } & $-0,0105$ & $-0,0079$ & $-0,0127$ \\
\hline & $(0,00)$ & $(0,00)$ & $(0,00)$ \\
\hline \multirow{2}{*}{ Constante } & 41,8773 & 34,8892 & 34,2882 \\
\hline & $(0,00)$ & $(0,00)$ & $(0,00)$ \\
\hline
\end{tabular}

Notas: p-valor entre parênteses; Grupo avaliado: mães inscritas no PBF, que recebem transferência em dinheiro; Grupo de controle 1: mães inscritas no PBF, que não recebem transferência em dinheiro; Grupo de controle 2: mães não inscritas no PBF, que pertencem ao público-alvo; Grupo de controle 3: mães não beneficiárias do $\mathrm{PBF}$, com renda familiar per capita igual ou inferior a $\mathrm{R} \$ 260,00$.

Fonte: PNAD (2004). 
Tabela A.3

\begin{tabular}{|c|c|c|c|}
\hline \multicolumn{4}{|c|}{ Equação de Seleção para a participação no mercado de trabalho } \\
\hline & Grupo de controle 1 & Grupo de controle 2 & Grupo de controle 3 \\
\hline \multirow{2}{*}{ Anos de escolaridade } & 0,0660 & 0,0320 & 0,0501 \\
\hline & $(0,00)$ & $(0,00)$ & $(0,00)$ \\
\hline \multirow{2}{*}{ Idade } & 0,1227 & 0,1008 & 0,1129 \\
\hline & $(0,00)$ & $(0,00)$ & $(0,00)$ \\
\hline \multirow{2}{*}{ Idade ao quadrado } & $-0,0016$ & $-0,0013$ & $-0,0014$ \\
\hline & $(0,00)$ & $(0,00)$ & $(0,00)$ \\
\hline \multirow{2}{*}{ Cor branca } & 0,0492 & $-0,0111$ & 0,0147 \\
\hline & $(0,00)$ & $(0,00)$ & $(0,43)$ \\
\hline \multirow{2}{*}{ Mãe chefe } & 0,1464 & 0,1969 & 0,1514 \\
\hline & $(0,00)$ & $(0,00)$ & $(0,00)$ \\
\hline \multirow{2}{*}{ Mãe com cônjuge } & $-0,1397$ & $-0,2743$ & $-0,2045$ \\
\hline & $(0,00)$ & $(0,00)$ & $(0,00)$ \\
\hline \multirow{2}{*}{ Norte } & 0,1302 & 0,0420 & 0,0187 \\
\hline & $(0,00)$ & $(0,00)$ & $(0,52)$ \\
\hline \multirow{2}{*}{ Nordeste } & $-0,1001$ & 0,1336 & $-0,0278$ \\
\hline & $(0,00)$ & $(0,00)$ & $(0,22)$ \\
\hline \multirow{2}{*}{ Sul } & 0,0425 & 0,3771 & 0,2073 \\
\hline & $(0,00)$ & $(0,00)$ & $(0,00)$ \\
\hline \multirow{2}{*}{ Centro-oeste } & $-0,0431$ & 0,1430 & $-0,0047$ \\
\hline & $(0,00)$ & $(0,00)$ & $(0,90)$ \\
\hline \multirow{2}{*}{ Região metropolitana } & $-0,1545$ & $-0,2569$ & $-0,1613$ \\
\hline & $(0,00)$ & $(0,00)$ & $(0,00)$ \\
\hline \multirow{2}{*}{ Região urbana } & $-0,2911$ & $-0,4015$ & $-0,3850$ \\
\hline & $(0,00)$ & $(0,00)$ & $(0,00)$ \\
\hline \multirow{2}{*}{$\mathrm{N}^{\mathrm{o}}$ de filhos de 0 a 5 anos } & $-0,2333$ & $-0,1329$ & $-0,1979$ \\
\hline & $(0,00)$ & $(0,00)$ & $(0,00)$ \\
\hline \multirow{2}{*}{$\mathrm{N}^{\mathrm{o}}$ de filhos de 6 a 10 anos } & $-0,0320$ & 0,0033 & $-0,0504$ \\
\hline & $(0,00)$ & $(0,00)$ & $(0,00)$ \\
\hline \multirow{2}{*}{$\mathrm{N}^{\circ}$ de filhos de 11 a 14 anos } & $-0,0257$ & 0,0760 & 0,0073 \\
\hline & $(0,00)$ & $(0,00)$ & $(0,59)$ \\
\hline \multirow{2}{*}{$\mathrm{N}^{\circ}$ de filhos de 15 a 18 anos } & 0,0210 & 0,0824 & 0,0262 \\
\hline & $(0,00)$ & $(0,00)$ & $(0,07)$ \\
\hline \multirow{2}{*}{$\mathrm{N}^{\mathrm{o}}$ de filhos de 19 anos ou mais } & 0,0366 & 0,0291 & $-0,0115$ \\
\hline & $(0,00)$ & $(0,00)$ & $(0,41)$ \\
\hline \multirow{2}{*}{$\begin{array}{l}\text { Renda domiciliar per capita } \\
\text { exceto a renda da mãe }\end{array}$} & $-0,0011$ & $-0,0024$ & $-0,0026$ \\
\hline & $(0,00)$ & $(0,00)$ & $(0,00)$ \\
\hline \multirow{2}{*}{$\mathrm{BF}$} & 0,0368 & 0,5388 & 0,1066 \\
\hline & $(0,00)$ & $(0,00)$ & $(0,00)$ \\
\hline \multirow{2}{*}{ Valor do BF } & $-0,0005$ & $-0,0011$ & $-0,0009$ \\
\hline & $(0,00)$ & $(0,00)$ & $(0,00)$ \\
\hline \multirow{2}{*}{ Constante } & $-1,8811$ & $-1,8027$ & $-1,5453$ \\
\hline & $(0,00)$ & $(0,00)$ & $(0,00)$ \\
\hline \multirow{2}{*}{ Razão de Mills } & $-2,2937$ & $-2,9257$ & $-1,4084$ \\
\hline & $(0,00)$ & $(0,00)$ & $(0,00)$ \\
\hline
\end{tabular}

Notas: p-valor entre parênteses; Grupo avaliado: mães inscritas no PBF, que recebem transferência em dinheiro; Grupo de controle 1: mães inscritas no PBF, que não recebem transferência em dinheiro; Grupo de controle 2: mães não inscritas no PBF, que pertencem ao público-alvo; Grupo de controle 3: mães não beneficiárias do PBF, com renda familiar per capita igual ou inferior a $\mathrm{R} \$ 260,00$.

Fonte: PNAD (2004). 